\title{
Characterization of mechanical and microstructural properties of palm oil fuel ash geopolymer cement paste
}

\begin{abstract}
This study delineates activation of palm oil fuel ash (POFA) by a combination of sodium silicate and sodium hydroxide at $60{ }^{\circ} \mathrm{C}$ to be used as a geopolymer binder. Qualitative observations as well as compressive strength were recorded to assess the viability of POFA utilization. Also, XRD, SEM/EDX, DSC, FTIR tests were conducted to investigate underlying mechanisms of geopolymerization. The post-test observations revealed that activation of POFA is applicable and compressive strength of up to $32.48 \mathrm{MPa}$ at the age of 28 days was achieved. Chemical tests indicated that formation of calcium silicate hydrate was the dominant cause of geopolymerization.
\end{abstract}

Keyword: Palm oil fuel ash; POFA; Alkali activation; Geopolymer binder 